\section{Solute Transport Modelling in Low-Permeability Homogeneous and Saturated Soil media}

Rudarsko-geološko-naftni zbornik

(The Mining-Geology-Petroleum Engineering Bulletin) UDC: $510.6 ; 551.1 / .4$

DOI: 10.17794/rgn.2021.2.3

Original scientific paper

\author{
Muhammad Zaheer ${ }^{1,2}$; Hadayat Ullah'; Saad Ahmed Mashwani'; Ehsan ul Haq'; \\ Syed Husnain Ali Shah'; Fawaz Manzoor ${ }^{1}$ \\ ${ }^{1}$ Department of Geology, Hazara University Mansehra 21300, Khyber Pakhtunkhwa, Pakistan \\ ${ }^{2}$ School of Environmental Studies, China University of Geosciences, Wuhan, 430074, China
}

\begin{abstract}
Fickian and non-Fickian behaviors were often detected for contaminant transport activity owed to the preferential flow and heterogeneity of soil media. Therefore, using diverse methods to measure such composite solute transport in soil media has become an important research topic for solute transport modeling in soil media. In this article, the continuous-time random walk (CTRW) model was applied to illustrate the relative concentration of transport in low-permeability homogeneous and saturated soil media. The solute transport development was also demonstrated with the convection-dispersion equation (CDE) and Two Region Model (TRM) for comparison. CXTFIT 2.1 software was used for CDE and TRM, and CTRW Matlab Toolbox v.3.1 for the CTRW simulation of the breakthrough curve. It was found that higher values of determination coefficient $\left(R^{2}\right)$ and lower values of root mean square error (RMSE) concerning the best fits of CDE, TRM, and CTRW. It was found that in the comparison of CDE, TRM, and CTRW, we tend to use CTRW to describe the transport behavior well because there are prevailing Fickian and non-Fickian transport. The CTRW gives better fitting results to the breakthrough curves (BTCs) when $\beta$ has an increasing pattern towards 2.oo. In this study, the variation of parameters in three methods was investigated and results showed that the CTRW modeling approach is more effective to determine non-reactive contaminants concentration in low-permeability soil media at small depths.
\end{abstract}

Keywords:

Low permeability; Relative Concentration; Non-Fickian; Continuous-Time Random Walk

\section{Introduction}

Transport through a porous medium leads the contaminant to spread into the other fluid medium. This consequence has been well modeled for homogeneous porous media at a large scale, such as $1250 \mathrm{~cm}$ (Xioang et al., 2006), however, only a handful of studies have attempted to understand the solute transport mechanism at a very small-scale. It is necessary to accurately characterize the early time behavior, such as solute introducing time for contaminants to escape from subsurface waste materials for groundwater remediation problems. Low-permeability environments are mostly associated with fine-grained sedimentary deposits such as shales and clays (Neuzil, 1994). Here, the term "low permeability" is applied to media with hydraulic conductivity to water of approximately $10^{-6} \mathrm{~cm} / \mathrm{s}$ or smaller (Liu et al., 2013).

There are very few solute transport modeling studies exclusively focusing on transport in low permeability porous media such as heavy silty clay and, to our knowl-

Corresponding author: Muhammad Zaheer

mzaqau@gmail.com edge, this is one of the smallest soil column experiments ( $3 \mathrm{~cm}, 5 \mathrm{~cm}$, and $8 \mathrm{~cm}$ vertically placed soil columns) which was used for Darcian velocities behavior and testing solute transport theories in laboratory scales (Zaheer et al., 2017). The fitting of relative concentration $\left(\mathrm{C} / \mathrm{C}_{0}\right)$ data by Convection-Dispersion Equation (CDE), sometimes shows inconsistency due to the non-Fickian behavior of solute transport, and CDE cannot explain this type of problem very effectively (Berkowitz et al., 2006). Margolin and Berkowitz (2012) and Köhne et al. (2009) investigated that the CDE model is based on the hypothesis that dispersion acts macroscopically as a Fickian process, with the dispersivity being assumed to be constant in space and time. Alternatively, it was focused on introducing new techniques to study the observed solute transport concentration behavior in various porous media. The TRM has the capacity of stimulating the asymmetric breakthrough curves of solute transport and thus it indicates the occurrence of preferential flow (PF) and the non-equilibrium mass-exchange between regions of different mobility (Hu et al., 2020). Conversely, CDE and TRM are less satisfactory in explaining certain $\mathrm{C} / \mathrm{C}_{0}$ features, particularly in the case of a decrease in tracer concentration, which can be ex- 
plained satisfactorily by the Continuous Time Random Walk (CTRW) model.

Cvetkovic et al. (2014) found that the CTRW model predicts solute transport due to the electrical conductivity distribution and the characteristic length. In this type of environment, non-Fickian particle dispersion is directly related to porous media characteristics. These studies suggest the mechanisms of non-equilibrium dispersion in heterogeneous porous media and provide a base for the predictive modeling of large-scale transport. Shahmohammadi-Kalalagh (2015) was indicated that the CTRW captures the full evolution of BTCs, and particularly at the early part of the breakthrough curves. Nevertheless, there is still a scarcity of transport model that enables a stronger identification and quantification of the small-scale solute transport modeling in low-permeability homogeneous and saturated soil media.

The purpose of this research is: (1) to interpret solute transport relative concentration $\left(\mathrm{C} / \mathrm{C}_{0}\right)$ obtained from a laboratory experiment (Zaheer et al., 2017) with $3 \mathrm{~cm}$, $5 \mathrm{~cm}$, and $8 \mathrm{~cm}$, vertically placed one-dimensional homogenous and saturated soil columns; (2) to obtain a best-fitting model for the identification of Fickian and Non-Fickian transport in low-permeability homogeneous and saturated soil media.

\subsection{Theories}

\subsubsection{Convective Dispersion Equation (CDE)}

The one-dimensional CDE for non-reactive solute transport through homogeneous soil is as (Gelhar et al., 1992; Rubin et al., 2012):

$$
\frac{\partial C}{\partial t}=D \frac{\partial^{2} C}{\partial x^{2}}-v \frac{\partial C}{\partial x}
$$

Where:

$$
\begin{aligned}
& \mathrm{C} \text { - solute concentration }\left(\mathrm{ML}^{-3}\right) \\
& \mathrm{D} \text { - hydrodynamic dispersion }\left(\mathrm{L}^{2} \mathrm{~T}^{-1}\right) \\
& \mathrm{t} \text { - time }(\mathrm{T}) \\
& \mathrm{v} \text { - average pore water velocity }\left(\mathrm{LT}^{-1}\right) \\
& \mathrm{x} \text { - distance }(\mathrm{L}) .
\end{aligned}
$$

For an initially solute-free and semi-infinite system, the analytical solution of CDE leads to the third-type (Dirichlet boundary condition) or flux type inlet boundary condition is (Parker and Genuchten, 1984):

$$
\begin{aligned}
C(\mathrm{x}, \mathrm{t}) & =\frac{C_{0}}{2}\left[\operatorname{erfc}\left(\frac{x-v t}{2 \sqrt{D t}}\right)+2 \sqrt{\frac{v^{2} t}{\pi D}} \exp \left(\frac{-(x-v t)^{2}}{4 D t}\right)-\right. \\
& \left.-\left(1+\frac{v x}{D}+\frac{v^{2} t}{D}\right) \exp \left(\frac{v x}{D}\right) \operatorname{erfc}\left(\frac{x+v t}{2 \sqrt{D t}}\right)\right]
\end{aligned}
$$

When the CDE is employed to compute the observed BTCs, vital distinction has been achieved between the observed and fitted BTCs, particularly for the late-time tailing portion of the curve, because it cannot effectively suit for non-Fickian transport behavior.

\subsubsection{Two region model (TRM)}

A two region model (TRM) is appropriate for nonequilibrium transport modeling, that is primarily because of physical and chemical phenomena (Kuntz, 2010), reflecting the heterogeneous characteristics of soils. TRM or MIM consists of a CDE Equation for solute transport in the mobile region, in concert with an expression, which illustrates the mass transfer of solute between mobile and immobile parts. The one-dimensional TRM for a mode of conservative solute transport through steady water flow is proposed by (Van Genuchten and Wierenga, 1976):

$$
\theta_{1} \frac{\partial \mathrm{C}_{1}}{\partial \mathrm{t}}+\theta_{2} \frac{\partial \mathrm{C}_{2}}{\partial \mathrm{t}}=\theta_{1} \mathrm{D}_{\mathrm{m}} \frac{\partial^{2} \mathrm{C}_{1}}{\partial \mathrm{x}^{2}}-\theta_{1} \mathrm{~V}_{\mathrm{m}} \frac{\partial \mathrm{C}_{1}}{\partial \mathrm{C}_{\mathrm{x}}}
$$

Where:

$$
\theta_{2} \frac{\partial \mathrm{C}_{2}}{\partial \mathrm{t}}=\omega\left(\mathrm{C}_{1}-\mathrm{C}_{2}\right)
$$

And the total water contents are equal to $\theta$ as:

$$
\theta_{1}+\theta_{2}=\theta
$$

$\theta$ - total water contents and here in the case of fully saturated media $\theta$ equal to porosity (n)

$$
\theta_{1} \mathrm{~V}_{\mathrm{m}}=\mathrm{q}
$$

Equation (6) shows the Darcy velocity $\left(\mathrm{LT}^{-1}\right)$. The TRM reduces to the CDE once the water content of the second region $\theta_{2}=0$, or once the rate of mass transfer is nonexistent, that is, $\omega=0$, and the parameters of the $\mathrm{CDE}$ are then $V=V_{m}$ and $\mathrm{D}=\mathrm{D}_{\mathrm{m}}$

The initial zero concentration and the third type inlet boundary condition for the semi-infinite system is used. TRM analytical solution in Laplace domain is (Toride and Van Genuchten, 1999; Gao et al., 2009):

$$
\begin{gathered}
\overline{C_{1}}(\mathrm{x}, \mathrm{u})=\frac{2 C_{0}}{u+u \sqrt{1+\frac{4 \mathrm{D}_{m} \zeta}{V_{m}}} \exp \left(\frac{V_{m}-\sqrt{V_{m}{ }^{2}+4 D_{m} \zeta}}{2 \mathrm{D}_{m}} \mathrm{x}\right)} \\
\mathrm{C}_{2}(\mathrm{x}, \mathrm{u})=\frac{2 \omega \mathrm{C}_{0}}{\left(\omega+\mathrm{u} \theta_{2}\right)\left(u+\frac{u \sqrt{1+4 D_{m} \zeta}}{V_{m}}\right)} \times \\
\quad \times \exp \left(\frac{V_{m}-\sqrt{V_{m}^{2}+4 D_{m} \zeta}}{2 \mathrm{D}_{m}} \mathrm{x}\right)
\end{gathered}
$$


Where:

$$
\xi=\left[\frac{\omega \theta_{2}}{\theta_{\mathrm{m}}\left(\omega+\mathrm{u} \theta_{2}\right)}+1\right]
$$

Where:

$\mathrm{u}$ is the Laplace variable, and its solutions can be inverted analytically by Toride and Van Genuchten (1995) or numerically supported the De Hoog et al. (1982).

A two-region model (TRM) is proposed to fit nonFickian BTCs and has effectively delineated a variety of various transport processes in homogeneous and heterogeneous porous media (Parker and Jardine, 1986).

\subsubsection{Continuous-time random walk (CTRW) model}

The continuous-time random walk (CTRW) theory provides a quantitative framework to clarify the Fickian and non-Fickian variety of transport behaviors. This framework is worth mentioning that the CTRW can capture the complete evolution of the solute breakthrough curve. The master equation conserving solute transport in the CTRW framework is a partial differential equation form. For all brief derivation subject to the transport equation, see Berkowitz et al. (2006). With the assumption of $\psi(s, t)=\psi(t) p(s)$, the transport equation can be written in the Laplace domain as Berkowitz et al. (2008):

$$
u \tilde{c}(s, u)-c_{0}(s)=-\tilde{M}(u)\left[v_{\psi} \nabla \tilde{c}(s, u)-D_{\psi}: \nabla \nabla \tilde{c}(s, u)\right]
$$

Where:

$$
v_{\psi}=\frac{1}{t_{1}} \int p(s) s d s-\text { tracer transport velocity which }
$$

might be different from the average fluid velocity

$\mathrm{D}_{\psi}=\frac{1}{\mathrm{t}_{1}} \int \frac{1}{2} \mathrm{p}(\mathrm{s}) \mathrm{ssds}-$ Dispersion coefficient

$\tilde{M}(\mathrm{u})=\mathrm{t}_{1} \mathrm{u}_{1} \frac{\tilde{\psi}(\mathrm{u})}{1-\tilde{\psi}(\mathrm{u})}-$ A memory function

$\mathrm{t}_{1}$ - characteristics time

$\mathrm{c}_{0}(\mathrm{~s})$ - initial concentration.

A form of $\psi(\mathrm{t})$ the truncated power law (TPL) can effectively apply to a wide range of physical scenarios The TPL form can be written as (Berkowitz et al., 2006):

$$
\psi(\mathrm{t})=\frac{\mathrm{n}}{t_{1}} \frac{\mathrm{e}^{\frac{-\mathrm{t}}{t_{2}}}}{\left(1+\frac{t}{t_{1}}\right)^{1+\beta}}, 0<\beta<2
$$

Where:

$$
\begin{aligned}
& n=\left[\left(\frac{t_{1}}{t_{2}}\right)^{\beta} e^{\frac{t_{1}}{t_{2}}} \Gamma\left(-\beta, \frac{t_{1}}{t_{2}}\right)\right]^{-1}-\text { normalized factor } \\
& \beta \text { - computed dispersion } \\
& \mathrm{t}_{2} \text {-cut-off time, as } \mathrm{t}_{2}>\mathrm{t}_{1} \\
& \Gamma(\mathrm{a}, \mathrm{x}) \text { are imperfect Gamma function. }
\end{aligned}
$$

Here in Equation (10), $\psi(t) \sim\left(\frac{t}{t_{1}}\right)_{-\mathrm{t}}^{-1-\beta}$ for $\mathrm{t}_{1}<<t<<\mathrm{t}_{2}$, this decreases exponentially $\psi(t) \sim e^{\frac{t_{2}}{2}}$ for $t>t_{2}$. For Fickian transport $\beta \geq 2$ and for non Fickian solute transport $0<\beta<2$, Whereas the smaller value of $\beta$, is, the more dispersive the transport behavior (Kuntz et al., 2011). The CTRW has been applied with success in a small soil column for the determination of Fickian and non-Fickian transport behavior.

\section{Material and Methods}

\subsection{Solute Relative Concentration $\left(C / C_{0}\right)$}

Solute Relative Concentration $\left(\mathrm{C} / \mathrm{C}_{0}\right)$ data was obtained by a tracer introducing test conducted by Zaheer et al. (2017) on $3 \mathrm{~cm}, 5 \mathrm{~cm}$, and $8 \mathrm{~cm}$ vertically placed soil column under steady-state and saturated flow conditions. $\mathrm{NaCl}$ was used as a tracer because it is easily accessible and dissolved $\mathrm{Cl}^{-}$has been commonly used as a conservative tracer in subsurface transport studies, as it exhibits a lack of adsorption. This feature was found in this experiment as well, which is very important and must be taken into account for analyzing the solute transport in low-permeability porous media (LPPM), such as clay. The concentration used in the experiments may be higher than values used in some other experiments, but this high value should not influence the conclusion of this research, as we were using the relative concentration, which is the ratio of actual concentration $(\mathrm{C})$ over the constant source concentration $\left(\mathrm{C}_{0}\right)$.

The test setup mainly consisted of a water-supply device (Mabottle), a Plexiglas column having a low-permeability porous medium (clay), and a water outflow installment (steady-flow water tank). In this experiment, clay soil samples were made as identical as possible. All impurities, such as gravel particles, residual leaves, roots, and other soil was removed and then the clay particles (heavy silty clay) with grain sizes smaller than 0.3 $\mathrm{mm}$ were used as the testing media. Since our focus was the physical process of the transport behavior, the minerals of the soil were not measured. A sieving method was used to make the samples identical. At the top of the columns, as a layer of $2 \mathrm{~cm}$ thickness with a filter paper below, it enclosed the soil to let the inflow solution be uniformly distributed throughout the entire soil surface in each column. Meanwhile, a sand layer of $5 \mathrm{~cm}$ thickness with a filter paper above, was put at the bottom of the columns to protect the soil at the exit. After this process, clean water was allowed to flow through the column to establish a stable flow condition to a reservoir containing a $\mathrm{NaCl}$ solution $\left(\mathrm{NaCl}+\mathrm{H}_{2} \mathrm{O}\right)$ to start the breakthrough process. Meanwhile, for the exit, a very small tank was used to guarantee a constant head boundary condition. 
Relative concentration $\left(\mathrm{C} / \mathrm{C}_{0}\right)$ was obtained by dividing the observed concentrations (C) by the initial $\mathrm{NaCl}$ solution concentration $\left(\mathrm{C}_{0}\right)$ and since the three soil columns $(3 \mathrm{~cm}, 5 \mathrm{~cm}$, and $8 \mathrm{~cm})$ reached 1 , this suggests a slight absorption of the $\mathrm{NaCl}$ solution in the transport process, hence in the latter part of the model, fitting the absorption clay was also not included. A complete presentation of this experiment can be seen from Zaheer et al. (2017).

\subsection{A criterion for Numerical Simulation}

The simulation process fits the $\mathrm{C} / \mathrm{C}_{0}$ data of three columns $(3 \mathrm{~cm}, 5 \mathrm{~cm}$, and $8 \mathrm{~cm})$, experiments with CTRW, TRM, and CDE. The serviceability of analysis contrasts in different methods describing the low-permeability medium solute transport law. In order to solve the Eqs. (1), (2), (3), and (4), we have used CXTFIT 2.1 (Toride and van Genuchten, 1999; Tang et al., 2010) software and CTRW Matlab Toolbox v.3.1. In this study, the average pore water velocities (v) and dispersion coefficient (D) were estimated from the observed relative concentration $\left(\mathrm{C} / \mathrm{C}_{0}\right)$ data and then using the nonlinear leastsquare parameter optimization code CXTFIT 2.1 of Toride et al. (1999). Initially, a solute-free and semi-infinite system, the analytical solution of $\mathrm{CDE}$ is subject to the flux-type inlet boundary condition. This code allows us to fit $\mathrm{v}$ and $\mathrm{D}$, to the measured breakthrough curves data. Once the $\mathrm{v}$ and $\mathrm{D}$ were estimated for each column, the dispersivity $(\alpha)$ was calculated using equation $\alpha=\mathrm{D} / \mathrm{v}$. Similarly, for TRM, the initial condition of zero concentration and third-type inlet boundary condition and four additional parameters (v, D, $\varphi$, and $\omega)$ were estimated. For the CTRW simulation of BTCs five parameters $\left(\mathrm{v}_{\psi}\right.$, $\mathrm{D}_{w}, \beta, \mathrm{t}_{1}$, and $\mathrm{t}_{2}$ ) were estimated, where $\mathrm{v}_{w}$ is transport velocity $\left(\mathrm{LT}^{-1}\right)$ and is different, which was used in the $\mathrm{CDE}$ and TRM (fluid velocity); $\mathrm{D}_{\psi}$ is generalized dispersion coefficient and varies with transport velocity or flow rate, thus changes the dispersive nature of transport, $\beta$ (by trial-and-error variations). The inlet boundary condition is a Robin type and the outlet boundary condition is a Neumann type (Margolin and Berkowitz, 2004; Perfect et al., 2002).

For fitting evaluation, determination of the coefficient $\left(\mathrm{R}^{2}\right)$, and root mean square error (RMSE) were used to determine the quality of fit. The difference in $\mathrm{R}^{2}$ for the "good" and "poor" models is the average around 0.98 , which for predictive purposes is excellent (Zaheer et al., 2017; Gao et al., 2009).

$$
\begin{gathered}
R^{2}=\frac{\left(\sum_{i=1}^{N}\left(C_{i c}-\bar{C}_{i c}\right)\left(C_{i m}-\bar{C}_{i m}\right)\right)^{2}}{\sum_{i=1}^{N}\left(C_{i c}-\bar{C}_{i c}\right)^{2} \sum_{i=1}^{N}\left(C_{i m}-\bar{C}_{i m}\right)^{2}} \\
R M S E=\sqrt{\frac{1}{N} \sum_{i=1}^{N}\left(C_{i c}-C_{i m}\right)^{2}}
\end{gathered}
$$

Where:

$\mathrm{N}$ - the number of concentrations

$\mathrm{C}_{\mathrm{ic}}$ - the estimated concentration

$\mathrm{C}_{\mathrm{im}}$ - the measured concentration,

$\bar{C}_{\mathrm{ic}}$ and $\bar{C}_{\mathrm{im}}$ - the mean values of $\mathrm{C}_{\mathrm{ic}}$ and $\mathrm{C}_{\mathrm{im}}$

\section{Results and discussion}

Figures 1, 2 and 3 show the observed and fitted BTCs for soil column lengths $3 \mathrm{~cm}, 5 \mathrm{~cm}, 8 \mathrm{~cm}$. The BTCs at each soil column length were individually fitted with CTRW, TRM, and CDE. The estimated parameters are listed in Tables 1 and 2. For the sensitivity of results, determination of coefficient $\left(\mathrm{R}^{2}\right)$, and root mean square error (RMSE) for CTRW, TRM, and CDE are presented in Table 3. The BTCs consistently fit the CDE, TRM,

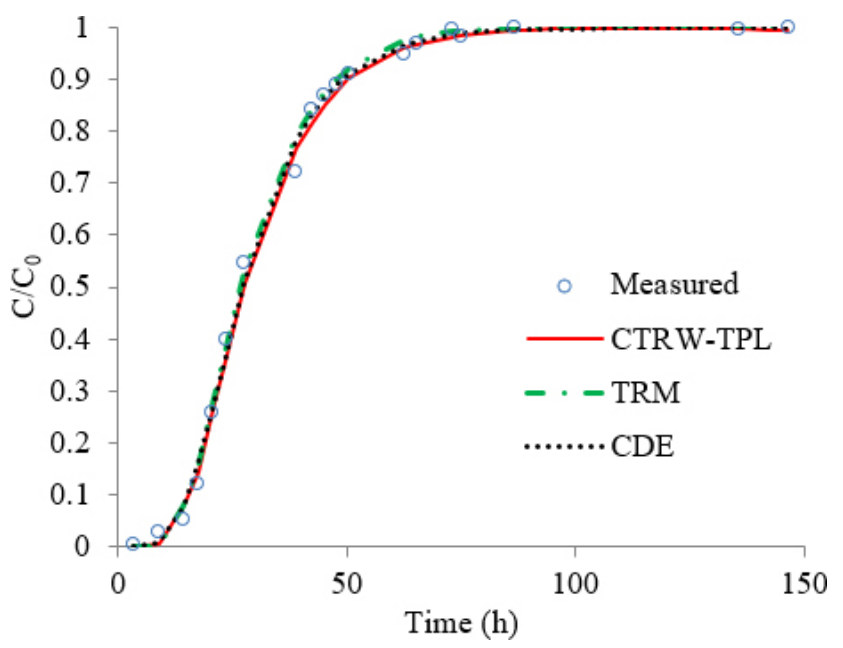

Figure 1: Breakthrough curves (BTCs) were separately fitted by using three methods (CTRW-TPL, TRM, and CDE) for $3 \mathrm{~cm}$ soil column

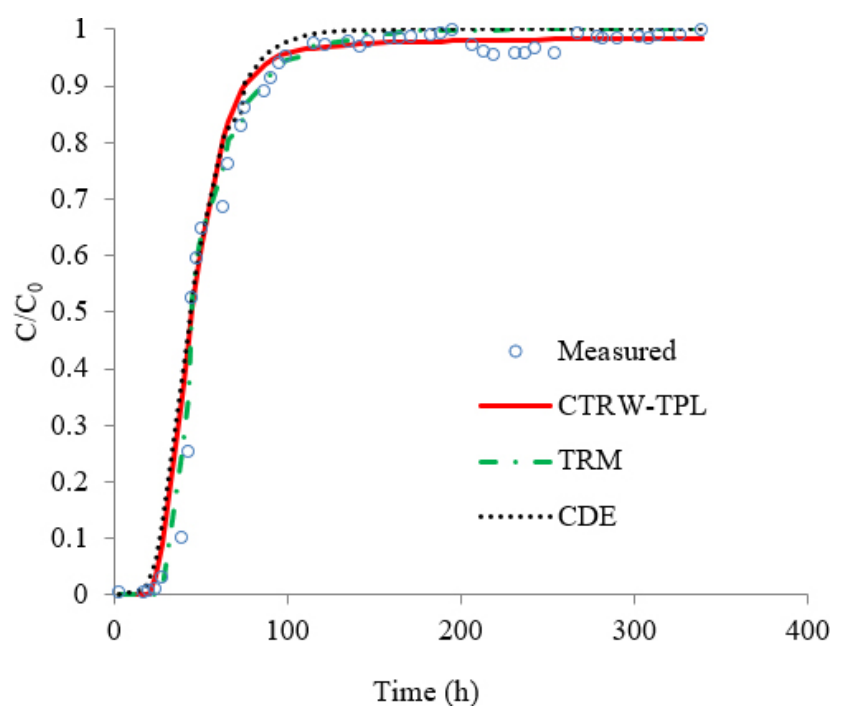

Figure 2: Breakthrough curves (BTCs) were separately fitted by using three methods (CTRW-TPL, TRM, and CDE) for $5 \mathrm{~cm}$ soil column 


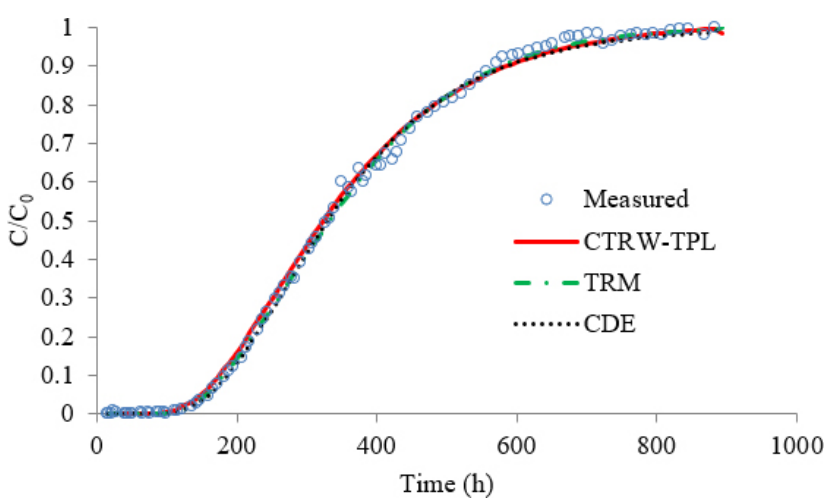

Figure 3: Breakthrough curves (BTCs) were separately fitted by using three methods (CTRW-TPL, TRM, and CDE) for $8 \mathrm{~cm}$ soil column

and CTRW show the corresponding values of $\mathrm{R}^{2}$ are all over 0.98 (see Table 3 ).

Rapid traverse solutes transport is observed in $3 \mathrm{~cm}$ and $5 \mathrm{~cm}$ clay soil columns (see Figures 1 and 2) because of sharp increases of seepage velocity, whereas a slow rise is observed during $0-200 \mathrm{~h}$ in the $8 \mathrm{~cm}$ soil column (see Figure 8). The $8 \mathrm{~cm}$ soil column is comparatively long, so seepage velocity is slow and solute transport needs more time. The CDE dispersivity $(\alpha)$ value 0.323 0.859 significantly increases with soil column length. As presented in Table 1, the fitted $\mathrm{v}$ and $\mathrm{D}$ values of CDE are increased for soil columns $3 \mathrm{~cm}$ and $5 \mathrm{~cm}$ and decreased for $8 \mathrm{~cm}$ soil column as can be seen in Figures 1, 2 and 3. The increased dispersion coefficient (D) for CDE shows some irregular transport behavior in the $3 \mathrm{~cm}$ and $5 \mathrm{~cm}$ soil columns. Similar results, as explained by Huang et al. (1995), show that high values of the dispersion coefficient (D) are the result of heterogeneities in the soil column. Pachepsky et al. (2000) came up with a similar result in the simulation of scale-dependent solute transport. The estimated $\alpha$ values are very close to 2.00 (see Table 1) and follow the CDE of the breakthrough curves in all Figures 1, 2 and 3.

The differences of dispersivity ( $\alpha$ ) that TRM fits for various soil columns are large and do not have any regularity. The mobile water fraction $(\varphi)$ is higher than the mass-transfer coefficient $(\omega)$ as shown in Table 1. The estimated values of mobile water fraction are between 0.424-0.847 (see Table 1). The variations of the $\varphi$ value for the $5 \mathrm{~cm}$ soil column in Figure 1(b) are the result of heterogeneities. Similar results were found by Huang et al. (1995). This higher degree of mobile water fraction $(\varphi)$

Table 1: Estimated values of parameters for CDE, TRM, and CTRW (TPL) for the relative concentration of $3 \mathrm{~cm}, 5 \mathrm{~cm}$, and $8 \mathrm{~cm}$, in low permeability homogeneous soil columns

\begin{tabular}{|c|c|c|c|c|c|c|c|c|}
\hline \multirow{2}{*}{$\begin{array}{l}\text { Soil } \\
\text { Column }\end{array}$} & \multicolumn{3}{|l|}{ CDE } & \multicolumn{5}{|l|}{ TRM } \\
\hline & $v(\mathrm{~cm} / \mathrm{h})$ & \begin{tabular}{|l|}
$D$ \\
$\left(\mathrm{~cm}^{2} / \mathrm{h}\right)$
\end{tabular} & \begin{tabular}{|l|}
$\alpha$ \\
$(\mathrm{cm})$
\end{tabular} & $\begin{array}{l}v \\
(\mathrm{~cm} / \mathrm{h})\end{array}$ & \begin{tabular}{|l|} 
\\
$\left(\mathrm{cm}^{2} / \mathrm{h}\right)$
\end{tabular} & \begin{tabular}{|l}
$\alpha$ \\
$(\mathrm{cm})$
\end{tabular} & $\varphi$ & \begin{tabular}{|l|}
$\omega$ \\
$(1 / h)$
\end{tabular} \\
\hline $3 \mathrm{~cm}$ & 0.099 & 0.032 & 0.323 & 0.099 & $1.00 \mathrm{E}-07$ & $1.01 \mathrm{E}-06$ & 0.558 & 0.086 \\
\hline $5 \mathrm{~cm}$ & 0.105 & 0.045 & 0.429 & 0.094 & 0.028 & 0.298 & 0.847 & 0.07 \\
\hline $8 \mathrm{~cm}$ & 0.022 & 0.0189 & 0.859 & 0.022 & 0.002 & 0.091 & 0.424 & 0.16 \\
\hline
\end{tabular}

Table 2: Estimated values of parameters for CTRW (TPL) for the relative concentration of $3 \mathrm{~cm}, 5 \mathrm{~cm}$, and $8 \mathrm{~cm}$, in low permeability homogeneous soil columns

\begin{tabular}{|l|c|c|c|c|c|}
\hline \multirow{2}{*}{$\begin{array}{l}\text { Soil } \\
\text { Column }\end{array}$} & \multicolumn{5}{|c|}{ CTRW (TPL) } \\
\cline { 2 - 6 } & $\begin{array}{c}\mathbf{v}_{\boldsymbol{\psi}} \\
(\mathbf{c m} / \mathbf{h})\end{array}$ & $\begin{array}{c}\mathbf{D}_{\boldsymbol{\psi}} \\
\left(\mathbf{c m}^{2} / \mathbf{h}\right)\end{array}$ & $\boldsymbol{\beta}$ & $\begin{array}{c}\mathbf{t}_{\mathbf{1}} \\
(\mathbf{h})\end{array}$ & $\begin{array}{c}\mathbf{t}_{\mathbf{2}} \\
\mathbf{( h )}\end{array}$ \\
\hline $3 \mathrm{~cm}$ & 0.288 & 0.094 & 1.348 & 0.01 & $1.19 \mathrm{E}+11$ \\
\hline $5 \mathrm{~cm}$ & 0.33 & 0.101 & 1.357 & 0.021 & $9.77 \mathrm{E}+08$ \\
\hline $8 \mathrm{~cm}$ & 0.032 & 0.031 & 1.68 & 0.0032 & 295000 \\
\hline
\end{tabular}

Table 3: Determination coefficient $\left(\mathrm{R}^{2}\right)$ and root mean square error (RMSE) for CDE, TRM, and CTRW (TPL) in three homogeneous soil columns

\begin{tabular}{|l|c|c|c|c|c|c|}
\hline \multirow{2}{*}{$\begin{array}{l}\text { Soil } \\
\text { Column }\end{array}$} & \multicolumn{2}{|c|}{ CDE } & \multicolumn{2}{c|}{ TRM } & \multicolumn{2}{c|}{ CTRW } \\
\cline { 2 - 7 } & $\mathbf{R}^{\mathbf{2}}$ & RMSE & $\mathbf{R}^{\mathbf{2}}$ & RMSE & $\mathbf{R}^{\mathbf{2}}$ & RMSE \\
\hline $3 \mathrm{~cm}$ & 0.997 & 0.024 & 0.997 & 0.024 & 0.997 & 0.027 \\
\hline $5 \mathrm{~cm}$ & 0.995 & 0.035 & 0.995 & 0.029 & 0.995 & 0.031 \\
\hline $8 \mathrm{~cm}$ & 0.999 & 0.016 & 0.999 & 0.014 & 0.999 & 0.016 \\
\hline
\end{tabular}

enhances the mixing area between the mobile and immobile regions and drives transport behavior towards the development of Fickian transport (Padilla et al., 1999). Estimated pore water velocities (v) are $0.022 \mathrm{~cm} \mathrm{~h}^{-1}-0.099$ $\mathrm{cm} \mathrm{h}^{-1}$ and decrease with the decrease of soil column length. This is because the TRM divides the solute into mobile and immobile regions. It was found that the mass transfer coefficient $(\omega)$, has the propensity to decrease with rapid traverse solutes transport as shown in Figures $\mathbf{1}$ and $\mathbf{2}$ and with soil column length (see Table $\mathbf{1}$ ).

The CTRW fitted value of velocity $\left(\mathrm{v}_{w}\right)$ is larger than the measured value of transport velocity (v), and dispersion $\left(D_{\psi}\right)$ is smaller than the estimated value of $D$ (see Table 2). These variations in $\mathrm{v}_{\psi}$ and $\mathrm{D}_{\psi}$ are attributed to the heterogeneous nature of the soil media (Rubin et al., 2012). As shown in Table 2 , the $\beta$ values are around 1.3 in Figures 1 and 2 and according to the CTRW theory the solute transport process is irregular within two soil columns, however, in the $8 \mathrm{~cm}$ soil column, $\beta$ is 1.68 (see Figure 3). The solute transport process is still irregular, but the value is closer to 2.00 . It was found that $\beta$ values 
increase with increasing soil column length, therefore relative concentration $\left(\mathrm{C} / \mathrm{C}_{0}\right)$ from non-Fickian to Fickian transport behavior is to be expected. Similar results concerning $\beta$, as explained by Xiong et al. (2006) and Dentz et al. (2004), which are parallel to these changes from non-Fickian to Fickian transport behavior have been observed in heterogeneous and homogeneous columns. However, very large values of cut-off time $\left(t_{2}\right)$ in Table 2 for the truncated power-law transition-time distribution function shows that Fickian transport has not developed. The median transition time $\left(\mathrm{t}_{1}\right)$ is very small concerning the time duration of the breakthrough curve. Eventually, the transition-time distribution is principally controlled by $\beta$ in Figures 1, 2 and 3. Gao et al. (2010) found similar results in simulating the non-Gaussian transport in the large heterogeneous soil column.

Breakthrough curves within the soil columns do not reach the inlet concentrations within the measured time as a result of tailing within the inlet position and from the above BTCs fitting and predicting results of various methods, it seems that the CTRW, TRM, and CDE can better describe the tracer concentration transport in the small homogeneous soil columns. For CDE dispersivity $(\alpha)$ values within the soil columns provides a suitable clarification for Fickian transport. As pointed out by Bromly and Hinz (2004), dispersivity variations are accredited to heterogeneities and CDE cannot present justification for the development of non-Fickian transport with distance in the soil column. TRM fitting results in the reorganization of the experiments shows just the opposite, suggesting that although TRM fits better, it remains to be further considered as a reasonable parameter. As pointed out in Gao et al. (2009), TRM might be performing better than CDE, as it can efficiently account for anomalous transport observed in the small homogeneous soil columns. However, TRM only uses a singlerate of mass transfer, therefore it did not describe the late-time tailing specifically.

The CTRW integrates the broad range of transition rates (Berkowitz et al., 2008) and it allows multiple rates of transport with power laws (Bromly and Hinz, 2004). Sequentially, it can better capture the full evolution of tracer migration in the soil column, particularly the distinct late-time tailing. After thoroughly discussing all the methods in BTCs, here the question arises "which model to choose from within the comparison" to describe the breakthrough? It has been concluded that, in the comparison of CDE, TRM, and CTRW models, analysis of the conservative tracer concentration in low-permeability media; we tend to use CTRW to describe the behavior well because Fickian and non-Fickian transport prevail there.

\section{Conclusions}

The tracer BTCs $\left(\mathrm{C} / \mathrm{C}_{0}\right)$ over time in one-dimensional low-permeability homogeneous and saturated media were evaluated with the CDE-based equilibrium model, the non-equilibrium TRM model, and by the CTRW (based on TPL) methods.

It was found that the magnitude of solute transport increases with the increasing length of the soil column and the presence of preferential flow in the soil column experiments quickens the rate of the penetration of a solute. Simulation results found that the rates of decrease of the CDE dispersion coefficients (D) suggest that Fickian transport exists in BTCs. The obvious Fickian transport in BTCs of soil columns is evident from the increasing pattern of $\beta$ values towards 2 in the light of the CTRW theory prediction and smaller values of $\omega$. The CDE, TRM, and CTRW give better fits to the BTCs with lower values of RMSE and higher values of $\mathrm{R}^{2}$.

The CTRW truncated power-law distribution function can quantify the full evaluation of breakthrough curves and for late-time tailing behavior. Consequently, it seems that the CTRW can be the dominant approach to simulate the Fickian and non-Fickian transport in low permeability homogeneous media. The analytic and numerical forms of CTRW will predict contaminated concentrations in downstream aquifers far earlier than CDE and TRM. Therefore, this study will be very helpful to identify and analyze the groundwater characteristics with the variation of soil permeability change at a small scale in low permeability porous media (LPPM).

\section{Acknowledgment}

This research did not receive any specific grant from funding agencies in the public, commercial, or not-forprofit sectors. Thank you editor and anonymous reviewers for your precious time to help us in the improvement of the manuscript.

\section{References}

Berkowitz, B., Cortis, A., Dentz, M. and Scher, H. (2006): Modeling non-Fickian transport in geological formations as a continuous-time random walk. Reviews of Geophysics, 44, 2, 177-186.

Berkowitz, B., Emmanuel, S. and Scher, H. (2008): Non-Fickian transport and multiple-rate mass transfer in porous media. Water Resource Research, 44, W03402, doi: 10.1029/2007WR005906.

Berkowitz, B. and Scher, H. (1998): Theory of anomalous chemical transport in random fracture networks. Physical Review E. 57, 5, 5858-5869.

Bromly, M. and Hinz, C. (2004). Non-Fickian transport in homogeneous unsaturated repacked sand. Water Resource Research, 40, 7, 1-12.

Cvetkovic, V., Fiori, A., and Dagan, G. (2014): Solute transport in aquifers of arbitrary variability: A time-domain random walk formulation. Water Resources Research, 50, 7, 5759-5773.

Dentz, M., Cortis, A., Scher, H. and Berkowitz, B. (2004): Time behavior of solute transport in heterogeneous media: 
transition from anomalous to normal transport. Advances in Water Resources, 27, 2, 155-173.

Gao, G., Zhan, H., Feng, S., Huang, G. and Mao, X. (2009): Comparison of alternative models for simulating anomalous solute transport in a large heterogeneous soil column. Journal of hydrology,377, 3, 391-404.

Gelhar, L. W., Welty, C. and Rehfeldt, K. R. (1992): A critical review of data on field-scale dispersion in aquifers. Water resources research, 28, 7, 1955-1974.

Huang, K., Toride, N., van Genuchten, M.T. (1995): Experimental investigation of solute transport in large, homogeneous and heterogeneous, saturated soil columns. Transport in Porous Media, 18, 283-302.

Köhne, J.M., Köhne, S. and Šimůnek, J. (2009): A review of model applications for structured soils: a) Water flow and tracer transport. Journal of Contaminant Hydrology, 104, 1-4, 4-35.

Kuntz, B. W., Rubin, S., Berkowitz, B., and Singha, K. (2011): Quantifying solute transport at the shale hills critical zone observatory. Vadose Zone Journal,10, 3, 843-857.

Le Borgne, T. and Gouze, P. (2008): Non-Fickian dispersion in porous media: Model validation from measurements at different scales. Water Resources Research, American Geophysical Union, 2008, 44, pp.W06427. -10.1029/2007 WR006279-. -insu-00373698-

Liu, K.., Wen, Z., Liang, X., Pan, H.Y. and Liu, J.G. (2013): One-dimensional column test for non-Darcy flow in low permeability media. Chinese Journal of Hydro Dynamics, $1,81-87$.

Margolin, G., and Berkowitz, B. (2004): Continuous time random walks revisited: first passage time and spatial distributions. Physica A: Statistical Mechanics and its Applications, 334, 1-2, 46-66.

Padilla, I. Y., Yeh, T. C. J. and Conklin, M. H. (1999): The effect of water content on solute transport in unsaturated porous media. Water Resource Research, 35, 11, 3303-3313.

Pachepsky, Y., Benson, D. and Rawls, W. (2000): Simulating scale-dependent solute transport in soils with the fractional advective-dispersive equation. Soil Science Society of America Journal, 64, 4, 1234-1243.

Perfect, E.M.C.S., Sukop, M.C. and Haszler, G.R. (2002): Prediction of dispersivity for undisturbed soil columns from water retention parameters. Soil Science Society of America Journal, 66, 3, 696-701.

Rubin, S., Dror, I. and Berkowitz, B. (2012): Experimental and modeling analysis of coupled non-Fickian transport and sorption in natural soils. Journal Contaminant Hydrology, 132, 28-36.

Shahmohammadi-Kalalagh S. (2015): Modeling contaminant transport in saturated soil column with the continuous time random walk. Journal of Porous Media, 18, 12,1181-1186.

Tang, G., Mayes, M.A., Parker, J.C. and Jardine, P.M. (2010) CXTFIT/Excel-a modular adaptable code for parameter estimation, sensitivity analysis and uncertainty analysis for laboratory or field tracer experiments. Computers \& Geosciences, 36, 9, 1200-1209.

Toride, N., Leij, F. J. and van Genuchten, M.T. (1999): The CXTFIT code for estimating transport parameters from laboratory or field experiments, version 2.1. Research Report. 137. U.S. Salinity Lab, Riverside, CA, USA.

$\mathrm{Hu}$, Y., Xu, W., Zhan, L., Ye, Z. and Chen, Y. (2020): NonFickian Solute Transport in Rough-Walled Fractures: The Effect of Contact Area. Water, 12, 7, 2049.

van Genuchten, M. T. and Wierenga, P. J. (1976): Mass transfer studies in sorbing porous media I. Analytical solutions. Soil Science Society of American Journal, 40, 4, 473-480.

Xiong, Y., Huang, G. and Huang, Q. (2006): Modeling solute transport in one-dimensional homogeneous and heterogeneous soil columns with a continuous-time random walk. Journal Contaminant Hydrology, 86, 3, 163-175.

Yetbarek, E., Kumar, S. and Ojha, R. (2020): Effects of soil heterogeneity on subsurface water movement in agricultural fields: A numerical study. Journal of Hydrology, 590, 125420.

Zaheer, M., Wen, Z., Zhan, H., Chen, X. and Jin, M. (2017): An experimental study on solute transport in one-dimensional clay soil columns. Geofluids, 2017, 1-17. 


\section{SAŽETAK}

\section{Modeliranje transporta otopine u niskopropusnome, homogenome i zasićenome tlu}

Fickovo i nefickovo ponašanje često se opaža kod prijenosa gdje postoji preferencijski tok i heterogenost tla (medija) kroz koji se događa protok. Stoga je uporaba različitih metoda mjerenja prijenosa otopina u takvim medijima važno područje istraživanja. Ovdje je prikazan model kontinuiranoga i vremenski slučajnoga gibanja (engl. skr. CTRW) kako bi se opisala relativna koncentracija tijekom prijenosa kroz niskopropustan, homogen i zasićen medij. To je demonstrirano konvekcijsko-disperzijskom jednadžbom (engl. skr. CDE) te dvočlanim modelom (engl. skr. TRM) i njihovom usporedbom. Programskim paketom CXTFIT 2.1 opisani su CDE i TRM, a paketom CTRW Matlab Toolbox v.3.1 model CTRW. Uočeno je kako veće vrijednosti koeficijenta determinacije $\left(R^{2}\right)$ te manje srednje kvadratne pogrješke (engl. skr. RMSE) najbolje opisuju podudaranje između CDE-a, TRM-a i CTRW-a. Usporedbom tih triju vrijednosti odabran je CTRW za opis ponašanja prijenosa, kako Fickova, tako i nefickova. CTRW se bolje podudara s krivuljama protoka (engl. skr. BTC), gdje $\beta$ raste prema vrijednosti 2 . Istražena je i promjena parametara u svim trima metodama, što je ponovno istaknulo CTRW kao najprimjereniji model u određivanju koncentracije nereaktivnih čestica u slabopropusnome tlu na malim dubinama.

\section{Ključne riječi:}

slaba propusnost; relativna koncentracija; nefickovo ponašanje; kontinuirano i vremenski slučajno gibanje

\section{Author's contribution}

Muhammad Zaheer (Ph. D in hydrology and water resources and Assistant Professor) prepared the idea, completed the literature review, participated in all work stages, and tested its correctness. Hadayat Ullah (M.Phil. in Geology); Syed Husnain Ali Shah (MS in Geology); Saad Ahmed Mashwani (MS in Geology) participated in mathematical parameter assessments. Ehsan ul Haq (Ph. D in Geology) participated in numerical simulations and remedying inconsistencies in the results. Fawaz Manzoor (MS in Geology) participated in proofreading regarding English and the final preparation of this manuscript. 